\title{
DEBATES
}

\section{A teoria da derivação do estado e o debate (alemão) do mercado mundial}

\author{
The theory of the derivation of the state and the (German) debate of \\ the world market
}

\section{Luiz Felipe Brandão Osório}

\section{Resumo}

Em meio a um contexto de crises econômicas e políticas, dentro da celebração do centenário da Revolução Russa e do bicentenário de Marx, o atual é voltar às origens marxianas para a compreensão da anatomia da sociedade capitalista. A mola mestra para a manutenção do modo de produção, o Estado, precisa ser destrinchada em sua real concretude. Para tanto, cabe entender o Estado enquanto forma política do capitalismo, como propóe o debate da derivação do Estado. Ainda, a unidade política territorial requer ser inserida no âmbito que busca oxigênio, as relaçôes internacionais, as quais manifestam a plena manifestação do capitalismo. Logo, o dentro das teorias da derivação, vem o debate (alemão) do mercado mundial, que traz a contribuição central para a sobrevivência do capitalismo: a multiplicidade estrutural de Estados.

\section{Palavras-chave}

Estado; Política; Capitalismo; Derivação; Mercado Mundial.

\begin{abstract}
Amidst a context of economic and political crises, within the celebration of the centenary of the Russian Revolution and Marx's bicentenary, it is nuclear to return to the Marxian origins to understand the anatomy of the capitalist society. The mainspring for the maintenance of the mode of production, the State, must be discussed in its real concreteness. For this, it is possible to understand the State as a political form of capitalism, as proposed by the State derivation debate. Moreover, the territorial political unity requires its insertion in the scope that gives it life, international relations, which manifest the full manifestation of capitalism. Thus, within derivation theories, comes the (German) world market debate, which brings the central contribution to the survival of capitalism: the structural multiplicity of states.
\end{abstract}

\section{Keywords}

State; Politics; Capitalism; Derivation; World Market. 


\section{Introdução}

Após os variados atestados de óbito dados pelos entusiastas da globalização, a discussão teórica do Estado retorna triunfalmente aos holofotes das pesquisas e da militância política. Vivendo em um contexto de crise mundial da acumulação capitalista, que impacta diretamente em movimentos conservadores e antidemocráticos pelos quadrantes do globo, é fundamental para a teoria marxista retomar a toada histórica. Mesmo porque golpes de Estado ocorrem por meio das estruturas burocráticas e do próprio direito estatal, colocando na encruzilhada tanto os defensores da mingua estatal como os entusiastas do normativismo. Assim, a procura por uma teoria radical que guie uma prática revolucionária é premente. E na cadência do marxismo é possível encontrar saídas.

O passo dado pelos primeiros intérpretes de Marx foi decisivo e viabilizou um fértil momento ocasionado pela janela científica aberta pela Revolução Russa para pensar o Estado e a política no capitalismo. As leituras foram direcionadas para o ínterim que a classe trabalhadora se reconhecia como tal e impunha suas reivindicaçôes. A postura revolucionária contemplou uma escrita transformadora que não se ateve à institucionalidade burguesa. $\mathrm{O}$ interregno do pós-Segunda Guerra, com as esquerdas no poder, quer pela via revolucionária, quer pela reformista ou democrática, viabilizou um pensamento voltado para a transformação das instituiçôes, do Estado e do direito, em prol de uma reforma ampla e estrutural. Com a queda do bloco socialista e a dissolução da União Soviética, o terceiro ciclo é de entropia pela derrota. A sensação de imobilidade não tardou a ser dissipada. Em menos de uma década (anos 1990), as reflexóes críticas retomam a dianteira, buscando superar o impasse entre reforma e revolução.

É nesse diapasão que se pretende aqui resgatar lições emanadas pioneiramente na década de 1970, mas que, no seu imediato desenrolar, não obtiveram maior alcance. Dentro dos impasses teóricos e práticos da esquerda, veio a leitura radical de Marx que norteou os debates da derivação do Estado, na Alemanha Ocidental. Era o crescimento das desilusóes com a socialdemocracia e o modelo de bem-estar social. Inserido na gama de discussóes que envolveram o debate, emerge o debate (alemão) ${ }^{1}$ do mercado mundial, o que se iniciou no país europeu, mas, posteriormente, ganhou o mundo. É com fulcro nesses pilares teóricos que se extrai a compreensão mais sofisticada dentro do espectro marxista sobre a relação entre o Estado e as formas

\footnotetext{
${ }^{1}$ Apesar de ter nascido na Alemanha, o debate não ficou a ela restrito, tendo angariado e influenciado autores de outros países, sobretudo na Europa Ocidental. Para mais ver Nachtwey e Ten Brink (2008).
} 
sociais da produção nas sociedades capitalistas. A separação entre política e economia não poderia ser tomada como um elemento dado, mas caberia explicá-la radicalmente: trazer a exposição da particularização do Estado enquanto forma social específica do capitalismo. Para tanto, como forma social, o Estado precisa ser compreendido por meio de sua derivação da crítica à economia política de Marx (ALMEIDA e CALDAS, 2017; BONNET e PIVA, 2017; HOLLOWAY, 2017; HIRSCH, 2017).

Em verdade, os debates da derivação do Estado marcam um recorte epistemológico nas leituras marxistas, inaugurando um novo panorama de ideias que pode demandar, inclusive, uma sistematização própria². Isso significa dizer que não se trata aqui de abordar um todo teórico uniforme e consoante. Há notórias divergências e célebres embates entre os intelectuais inseridos nessa seara. Em comum, apenas o ponto de partida, podendo chegar a conclusóes e percepçóes distintas e opostas. Em outras palavras, o que unifica é a abordagem do Estado e da política enquanto formas sociais extraídas ou, mais precisamente, derivadas das relações sociais de produção capitalistas (MASCARO, 2013; 2018). A partir desse passo, constrói uma teoria do Estado burguês que oferece uma relevante interpretação sobre os debates hodiernos.

Munido desse escopo, inicia-se uma narrativa que passará pelo aspecto geral da releitura de Marx nos anos 1960 e 1970, encetada na República Federal da Alemanha, a qual sairá do gueto acadêmico, reverberando em outras partes do mundo. Logo, a primeira tarefa é perpassar brevemente o debate da derivação do Estado e do direito, para que se possa caminhar rumo a um vetor desse conjunto, o debate do mercado mundial. Após a investigação da interface entre relações internacionais, mercado mundial e Marx, caberá especificar autores como Neusüss, Busch e, notadamente, Braunmühl. O desenho dessa demarcação engloba nas teorias do Estado tanto a vertente do marxismo ocidental ${ }^{3}$ quanto o que se convencionou

\footnotetext{
${ }^{2}$ Dentro da crítica seria possível estabelecer um novo universo organizado pelo mesmo método, em visóes economicistas e politicistas. Essa sistematização das novas leituras de Marx é feita com maior densidade por Caldas (2015); Elbe (2010) e Mascaro (2018).

${ }^{3}$ Segundo Elbe (2010), o chamado marxismo ocidental, que abrange o interregno de 1923 até cerca de meados da década de 1960. Em suas teorizaçóes é possível encontrar indícios do humanismo e da valoração da subjetividade, conforme presente nos escritos iniciais de Marx. O foco dessas abordagens reside muito mais na autonomia dos elementos superestruturais em relação sua base econômica, destacando as nuances da política, do direito e da ideologia como aspectos transformadores.
} 
chamar de novo marxismo ${ }^{4}$, o que imputou às teorias do Estado um emaranho mais amplo que precisa ser bem delineado.

Desse modo, uma contextualização faz-se necessária. O momento do debate é o da decadência e (consequente e rápida) retomada da hegemonia estadunidense (a partir da ofensiva e da consequente derrota das experiências de socialismo real na União Soviética e no Leste Europeu); da desilusão das esquerdas com o modelo de bem-estar social e em relação à socialdemocracia; da intensificação do processo de internacionalização das relações de produção pelo mundo (JESSOP, 1991); da retomada das reflexóes teóricas marxistas sobre o Estado. É nesse diapasão que se pode mapear o amplo e difuso universo teórico (CARNOY, 1994; HIRSCH, 2010; HIRSCH, KANNANKULAM e WISSEL, 2017; MASCARO, 2013).

Em meio à ofensiva neoliberal pela década de 1980, assim como vieram à tona, em pouco tempo, as contestaçôes submergiram ante a onda da modernização globalizante. Nesse sentido, a década de 1990 não apenas assinalou o encerramento da transição, com o apogeu da estratégia neoliberal, mas também o combate ferrenho das teorias do Estado com a emergência de concepções teóricas na direção adversa, de enfraquecimento e de demonização do aparato estatal e da política. Para o marxismo,

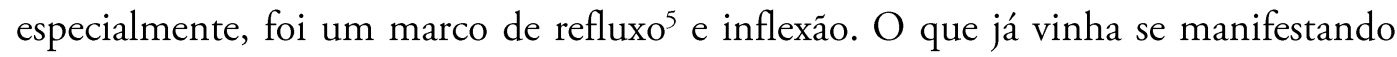
nos escombros da periferia e nos poróes do capitalismo, oportunamente relegado pelos grandes centros, a enorme insatisfação com as ilusôes da globalização explodiu. Não tardou para o desnude das falácias neoliberais logo no início dos anos 2000 e a renovação da discussão teórica do Estado.

\section{O debate da derivação do Estado}

A nova leitura do marxismo emerge, conforme Elbe (2010), a partir de 1965. Com fulcro no Marx da maturidade, apropria-se dos Grundrisse e d'O Capital Volume I, e das categorias econômicas nele anunciadas, como arcabouço para a

\footnotetext{
${ }^{4} \mathrm{O}$ termo não é o melhor, pois o adjetivo novo sempre traz falsos revestimentos para velhas problemáticas. É importante frisar, contudo, é que a expressão se refere à nova leitura do marxismo, conforme Elbe (2010), a partir de 1965. O resgate feito é o das categorias econômicas anunciadas por Marx n'O Capital, como arcabouço para a construção de uma teoria política ou do Estado no capitalismo. A ruptura com o marxismo ocidental gerou desdobramentos teóricos em diversos países, a partir dos anos 1970, como Alemanha, Inglaterra, Itália e França.

${ }^{5}$ Cabe aqui ressaltar as honrosas e relevantes exceçóes que marcaram a contestação da época à globalização, como o zapatismo, no México, em 1994, a grande manifestação de Seattle, em 1999, nos Estados Unidos, e o Fórum Social Mundial de Porto Alegre, em 2001, no Brasil.
} 
construção de uma teoria política crítica do capitalismo (MARX, 2013). Entre os prenunciadores está Pachukanis. O ponto de partida é a leitura de Althusser, que reverberou desdobramentos teóricos em diversos países, como Alemanha, Inglaterra e França. Com divergências internas, mas com muitas convergências, solidificaram interpretaçôes acerca do Estado e do capitalismo. Esse universo que se descortina é tão amplo que é possível tecer inúmeras subdivisóes e classificaçóes, o que, definitivamente, não caberá a esta pesquisa. $O$ caminho que será ressaltado se direciona por meio da retomada da economia política de Marx e do resgate do horizonte teórico do Estado e do direito (originalmente ambos com raízes no pensamento de Pachukanis), a teoria derivacionista, desenvolvida na República Federal da Alemanha, que reposiciona a compreensão teórica e política do Estado e do capitalismo no tempo presente.

O tempo e o espaço dessa inflexão teórica são bem específicos e importantes na consideração de seu desenvolvimento. A República Federal da Alemanha, na década de 1960, já digerira os efeitos do pós-guerra. Os anos seguintes ilustraram o momento de dissipação das ilusórias promessas de prosperidade do mundo capitalista. Passada a recuperação econômica célere dos primeiros anos de vitrine capitalista, o milagre alemão, havia grande decepção política entre a intelectualidade contestadora, que se canalizou em diversos protestos estudantis e político-partidários. O país já ensaiava caminhar com as próprias pernas. Ao mesmo tempo em que também passava a sofrer os impactos da economia mundial. Em meio a um contexto de crise internacional, os primeiros percalços foram consideravelmente sentidos. Dentre os motivos elencados para o surgimento da concepção teórica em solo alemão, cabe a consideração de importantes aspectos históricos (ALTVATER e HOFFMANN, 1990; BONNET, 2007). O enfraquecimento da tradição crítica e marxista, inicialmente gestada na Escola de Frankfurt, mediante a ascensão do nazismo e da vulgarização stalinista. A marginalização e criminalização da esquerda durante $o$ governo de Konrad Adenauer. A recessão, novidade após anos de milagre econômico, entre 1966 e 1967, impactou na configuração política do país. A vitória do partido socialdemocrata (SPD) nas eleições de 1969 fortificou o discurso de reformas. A ebulição dos movimentos estudantis na França e na Inglaterra ascendeu o pavio da insatisfação ${ }^{6}$. Assim, veio à tona o debate sobre os limites e a atuação do ente estatal.

${ }^{6}$ Durante a década de 1960, mais especificamente em maio de 1968, protestos estudantis e greves operárias pararam o país, sendo duramente reprimidos e reverberando efeitos pelo mundo. $\mathrm{Na}$ Alemanha Ocidental, as mortes de líderes estudantis e a desarticulação entre o movimento estudantil e 
O Estado de bem-estar social era, na visão crítica, um amplo aparato burocrático de controle social, que perpetuava a mesmice política, com praticamente um modelo único, a socialdemocracia e seus contornos particulares. Em meio à ortodoxia do marxismo soviético e o reformismo acomodado da socialdemocracia, soluçôes à esquerda prescindiam.

O âmago dessa releitura do Estado no capitalismo perpassa a tradicional incômoda pergunta de Pachukanis: por que a dominaçáo de classe não se apresenta como ela é, a sujeição de parcela da sociedade ante a outra, mas, por meio de um aparato público coercitivo, apresenta-se como dominação impessoal e oficial.

Por detrás de todas estas controvérsias, está colocada uma única questão fundamental: por que é que a dominação da classe não se apresenta como ela é, ou seja, a sujeição de uma parte da população à outra, mas assume a forma de uma dominação estatal oficial ou, o que dá no mesmo, por que o aparelho de coerção estatal não se constitui como aparelho privado da classe dominante, mas se destaca deste, assumindo a forma de um aparelho público impessoal, separado da sociedade (PACHUKANIS, 2017, p. 143).

Em outras palavras: pelo método da teoria da forma-valor de Pachukanis ambicionou-se explicar a separação constitutiva entre Estado e capital ou o porquê a clivagem entre política e economia, e a consequente autonomia relativa do Estado, que não é um palco em disputa, mas é inerente às relaçôes de produção capitalista. É nesse cerne que, desde o artigo cardial de Müller e Neusüss (1978), A ilusão do Estado de bem-estar social e a contradição entre capital e trabalho ${ }^{7}$ de 1970, publicado no ano seguinte no periódico, as visões derivacionistas do Estado Os autores axiais calcam sua argumentação na formulação de estratégias políticas e

o operário (tido como reformista) expuseram as fraturas e as particularidades do contexto germânico. Logo após os incidentes e nos desdobramentos da década de 1970 surgiram grupos armados de guerrilha urbana, como o RAF (Rote Armee Fraktion) também conhecido como grupo BaaderMeinhof.

7 Em alemão, lê-se: Die Sozialstaatsillusion und der Widerspruch von Lohnarbeit und Kapital, Publicado no número inaugural da revista PROKLA (acrônimo do termo em alemão Probleme des Klassenkampfs, que significa problemas da luta de classes), em 1971, em meio ao contexto de ebulição do final dos anos 1960 e da crise que se avizinhava na década seguinte, sendo o vetor primordial para a difusão dos debates derivacionistas, $\mathrm{O}$ texto é neste artigo referenciado na bibliografia por sua publicação no livro de 1978, que reuniu e difundiu os autores do debate da derivação do Estado, organizado por Holloway e Picciotto. 
modos de organização da classe trabalhadora, com fulcro no desenvolvimento do movimento trabalhista na história, pautados pela bifurcação entre reformismo e revolução.

O vocábulo derivação advém do substantivo Ableitung, da língua alemã, o que não significa que haja uma simples determinação, sendo o Estado mero resultado da vontade da classe dominante, mas, sim, de um determinado modo de produção e das relaçôes sociais que lhe são inerentes e diferenciadoras dos modos anteriores. Daí o estudo da especificidade do Estado no capitalismo (CALDAS, 2015). Nesse diapasão, a teoria da derivação representa um caminho de superação aos impasses políticos. Em meio à falência do modelo de bem-estar social, a emergência do neoliberalismo e engessamento das leituras de tipo soviético, a esquerda, nesta encruzilhada, vinha refluindo, reduzindo-se a apenas uma postura de resistência ao neoliberalismo, sem proposições alternativas de construção de perspectivas socialistas. No seio das contradições extremas do capitalismo desenvolvido de bem-estar social e já entrevista a crise da experiência soviética, o marxismo avança para compreender o Estado a partir das categorias que estruturam a sociedade capitalista.

Nessa toada, a chegada ao socialismo se daria por caminhos distintos, ou por reformas institucionais e legais ou pela insurreição da classe trabalhadora, uma vez que a via estatal é inerentemente obstaculizada. Cada qual se embasa em perspectivas opostas no tocante ao papel do Estado. Entre o capitalismo monopolista de Estado (Stamokap), cuja elaboração teórica aponta a atuação do aparato estatal direcionada a atender as demandas da acumulação de capital, do economicismo, e o capitalismo tardio (Spätkapitalismus) ou teoria da socialdemocracia de Estado, defensor da segregação da política da análise da acumulação de capital, própria do politicismo, o debate alemão da derivação do Estado (Staatsableitungsdebatte) oferece alternativas.

O debate da derivaçáo do Estado, instigado pela releitura da obra seminal de Marx (O Capital) consegue estabelecer-se mediante a visão de que os escritos marxianos não se vinculavam à análise econômica, mas, sim, à crítica materialista da economia política. Em outras palavras, a crítica materialista da tentativa da burguesia de discutir a economia isoladamente no tocante à relação exploratória de classes em que ela se funda. Logo, as categorias desenvolvidas n'O Capital, como mais-valor, valor, acumulação, lucro, preço, salário, não servem apenas para o debate econômico específico, mas são essenciais para uma discussão ampla, também política, pois são categorias histórico-materialistas desenvolvidas para iluminar a estrutura de classes na sociedade capitalista e as formas e concepçôes gerais dessa estrutura. A crítica à 
economia política operada por Marx é condensada na noção de que as categorias econômicas são a aparência de fetiches das relaçôes sociais. Assim, os conceitos não serão estritamente políticos ou econômicos, mas capazes de apreender criticamente o conteúdo das formas política e econômica das relações sociais. Cumpre, portanto, a compreensão do Estado e da política a partir de sua derivação da categoria de capital. Em outras palavras, o eixo fundamental dessas análises é a ênfase na necessidade de explicar a separaçáo entre as esferas da política e a da economia pela perspectiva do capital. "Assim, as formas específicas econômica e política não podem ser tomadas como dadas, mas precisam ser derivadas das categorias fundamentais das relaçóes sociais de produção, para que se estabeleça simultaneamente sua distinção e sua complementariedade" (CLARKE, 1991, p. 10, tradução nossa).

O Estado burguês ganha especificidade como uma entidade fora e, ao mesmo tempo, ao lado da sociedade burguesa. A concentração da sociedade na forma estatal, que se coloca externa a ela mesma, parecendo flutuar sobre sua própria existência, é fulcral, pois somente assim pode garantir a manutenção e a reprodução da sociedade capitalista, âmbito internamente contraditório permeado pelas relações de produção. Com efeito, a relação entre economia e política não requer ser pensada pela dinâmica tradicional entre estrutura e superestrutura (muito vulgarmente atribuída a Marx por leituras mais ortodoxas), mas o ponto nodal está no motivo pelo qual as relaçôes sociais em uma sociedade burguesa aparecem em formas separadas, como relaçóes políticas e relaçôes econômicas. O Estado precisa ser visto enquanto forma específica de uma dominação histórica de classe. Com fulcro na vertente derivacionista do novo marxismo, é fundamental proceder a uma mirada na totalidade das relaçóes sociais capitalistas, realizando a derivação necessária das categorias políticas, extraídas das econômicas, para situar as questôes estruturais.

O que essa visão apregoa é que se deve derivar as categorias políticas e o Estado das relações sociais da produção capitalista. O que ocorre, para alguns, pela via lógica (Escola Lógica do Capital) ou pelo caminho da factualidade (contraditoriedade, como o faz a teoria materialista do Estado), para mostrar a diferenciação entre as esferas política e econômica como consequência da forma social da produção capitalista, e pela via histórica, que ressalta a clivagem como um construto da trajetória concreta das relaçôes sociais.

$\mathrm{O}$ artigo pioneiro de Müller e Neusüss inspirou e carreou uma geração de pensadores, que se ocuparam de uma ampla releitura do marxismo a partir dos aspectos essenciais da sociedade capitalista. Inicialmente, constando na obra organizada conjuntamente por Holloway e Picciotto, as primeiras respostas vieram de 
Altvater, Hirsch, Blanke, Jürgens, Kastendiek, Gerstenberg, Reichelt e Braunmühl, tendo cada qual assumido uma ênfase específica ${ }^{8}$. A tendência foi o alargamento do debate, não apenas pela Alemanha, mas por outros países europeus. Conforme mapeado por Altvater e Hoffmann (1990), Bonefeld e Holloway (1991), Bonnet (2007), Míguez (2010), Caldas (2015) e Gerstenberg (2010), os expoentes dessa corrente advém dos círculos universitários, majoritariamente da Alemanha, notadamente de Berlim e de Frankfurt am Main, interconectados com outros da Itália ${ }^{9}$, da França ${ }^{10}$ e da Inglaterra ${ }^{11}$, desde sua exaltação pela publicação britânica State and Capital: a Marxist Debate, organizado pelos estudiosos entusiastas das ideias John Holloway e Sol Picciotto, em 1978, quando a concepção derivacionista reverberou-se mundialmente, para além das universidades alemãs.

O debate da derivação do Estado irrompe essas barreiras ao alicerçar a especificidade tanto da política quanto do desenvolvimento das formas políticas na análise da produção capitalista, franqueando alternativas teóricas e políticas. Por um lado, o curso do desenvolvimento econômico e social de sociedade capitalista não pode depender meramente do desdobramento das leis econômicas, sem considerar o relevante papel da luta de classes. Por outro lado, o resultado desse embate de classes não será determinado apenas pela vontade das forças em disputa, há que se ter em mente a estrutura econômica, política e ideológica em que a luta de classes se manifesta. Nem instrumento da classe capitalista dominante, nem terreno neutro de conquista pela luta de classes, a compreensão do Estado e do capitalismo, em um

\footnotetext{
8 É Gerstenberg (2010) que faz o diagnóstico dos autores divididos por ênfases temáticas.

${ }^{9}$ Míguez (2010) e Mascaro (2018) incluem Toni Negri e Mário Tronti na vertente italiana das leituras derivacionistas.

${ }^{10}$ Caldas (2015) elenca na corrente francesa do derivacionismo ou de proximidades fortes a ela, desde pensadores mundialmente renomados, como Louis Althusser, Nicos Poulantzas e Étienne Balibar até os teóricos da regulação econômica, como Alain Lipietz, Robert Boyer e Michel Agliettà.

${ }^{11} \mathrm{Na}$ Inglaterra, particularmente, os debates teóricos floresceram com maior força após a Conferência dos Socialistas Econômicos (CSE- Conference of Socialist Economists), que reabriu as discussóes sobre as categorias econômicas marxianas, como valor, processo de trabalho, Estado, mercado mundial e forma social como ilustraçóes de uma crítica ferrenha às até então preponderantes premissas do keynesianismo e do neoricardianismo. A vertente teórica do Open Marxism tem nesse evento um pilar fundante. Caldas (2015) aponta John Holloway, Sol Picciotto, Bob Jessop, Werner Bonefeld e Simon Clarke, seguindo as diretrizes do movimento, cujos parâmetros teóricos estão traçados nos três volumes homônimos que reúnem ensaios dos autores que compóem esse grupo teórico. Para mais ver Clarke (1991).
} 
contexto de falência e ilusóes da socialdemocracia, passava pela costura da interface entre economia e política, diferenciando-se das duas anteriores.

Dentro do debate derivacionista do Estado, diversas correntes se apresentam, dentre as quais o maior relevo caberá ao debate do mercado mundial e à teoria materialista do Estado, cuja interface será o cume desse trabalho, constituindo o arcabouço imprescindível para a compreensão do Estado e da forma política no capitalismo.

\section{O debate (alemão) do mercado mundial}

Dentro do debate da derivação do Estado, paralelamente, como um subconjunto, uma das vertentes no amplo espectro da derivação, na compreensão do Estado e da política a partir das categorias econômicas marxianas do capital, emerge como um tema crucial na análise marxista: o mercado mundial. Desde os primeiros escritos de Marx e em toda sua obra, a tendência expansionista do capital é enfatizada. $\mathrm{O}$ desenvolvimento histórico do capitalismo (e do imperialismo) comprova a imprescindibilidade de sua abordagem para uma ampla compreensão. $\mathrm{O}$ esgarçamento do capitalismo ocorre por meio e, ao mesmo tempo, resulta na forma mais desenvolvida do capitalismo, o mercado mundial.

A vertente não se limita, mas parte de autores alemães, originalmente, para ganhar contornos mundiais. Nesse diapasão, a clivagem entre as esferas econômica e política constituída nas relações capitalistas de produção, que garante a especificidade do modo de produção, precisa ser analisada em seu conjunto. Isso significa que a lente requer ser ampliada para a esfera internacional. Notadamente, em meio aos impasses da década de 1970, a necessidade de retorno às raízes marxianas atingiu a concepção de mercado mundial, captado como ponto essencial na acumulação capitalista.

Especialmente, no caso alemão, a inserção internacional e a estrutura social nacional estimularam o aprofundamento do tema. $\mathrm{Na}$ Alemanha Ocidental verificouse a efervescência de ideias sobre aquele momento de inflexáo no capitalismo pelo globo. Isso não aconteceu nesse país fortuitamente. Tendo em vista sua posição peculiar no sistema de Estados do pós-Segunda Guerra, a República Federal da Alemanha de inimigo de guerra foi içada à categoria de parceiro estratégico, recebendo apoio material direto e indireto para sua recuperação econômica. Desenvolvida à convite, a economia germânica foi amalgamada no comércio internacional, o qual passou a responder por parcela significativa de seu produto interno bruto. Destarte, vulnerável às crises externas, as desilusôes com o arranjo do 
pós-guerra são descortinadas. Após de uma década de célere crescimento econômico, a economia política alemá revelava seu real caráter, reformista, conciliatório e não transformador, apoiado em um Estado de segurança, vigilante, que fomenta o compromisso de classes e a manutenção do capitalismo. A insatisfação foi o fermento para a investigação das entranhas do capitalismo em terras germânicas.

$\mathrm{Na}$ radiografia marxista do Estado, Christel Neusüss, Klaus Busch e Claudia von Braunmühl desenvolveram suas interpretações acerca das relações internacionais, partindo das premissas derivacionistas. Nelas a releitura da crítica à economia política de Marx trazia a tendência inerente de internacionalização do capital para aspectos nodais da discussão por saídas à esquerda. Suas formulaçôes teóricas ficaram conhecidas como debate do mercado mundial (Weltmarktdebatte) ${ }^{12}$. Pode considerar-se mesmo um debate no sentido do confronto de interpretaçôes, visto que, apesar de muitos pontos convergentes, há também divergências significativas entre elas.

O liame que unifica as teorias do mercado mundial é a base derivacionista do resgate da análise da teoria da forma valor (Wertformanalyse) para explicitar a separação constitutiva entre Estado e capital. Essa clivagem entre esfera política e econômica, e a relativa autonomia do Estado dela decorrente, são elementos estruturantes próprios da forma política do capitalismo, sem os quais resta inviabilizada a reprodução das relações de produção capitalistas. O mercado mundial é a manifestação mais completa e desenvolvida do movimento do capital, o espaço necessário e fundamental para a compreensão do capital em sua plenitude e do fenômeno político. Os três buscam reconstruir a análise marxiana do capitalismo por meio da descrição e da reflexão teórica sobre como a lei do valor opera no mercado mundial, no qual os processos econômicos ganham vida própria no tocante aos atores envolvidos. Assim, a conexáo que molda o debate do mercado mundial pode ser delineada.

A forma-valor (dinheiro e capital) e a lei do valor (mercado) impóem uma lógica particular sobre as pessoas e tornam uma forma de racionalidade plausível a elas- a pressão que impacta pelas costas dos sujeitos. Capitalismo como uma sociedade descentralizada caracterizada

\footnotetext{
${ }^{12}$ Cabe pontuar que os três autores escolhidos são justificados pelo vínculo ao debate derivacionista e ao entorno intelectual do periódico PROKLA. O destaque dos três não exclui outras eventuais contribuições existentes que, por não terem conexão direta com esses cânones, não serão abordadas.
} 
por crises, competição e luta de classes (os três Cs) regula a si mesmo desse modo, mas o processo só é permanente se o Estado capitalista é capaz de constituir-se e sobreviver como uma instância separada relativamente autônoma (NACHTWEY e TEN BRINK, 2008, p. 42, tradução nossa).

A despeito das simetrias no pensamento, há uma clivagem importante no debate do mercado mundial. De um lado estão Neusüss e Busch e, de outro, Braunmühl (que complementa e, portanto, diferencia sua visão com elementos da teoria materialista do Estado). Para os dois primeiros, a reconstrução da lei do valor marxiana requer ser ampliada também para a esfera internacional. A análise do movimento de capital no mercado mundial não pode ser derivada simplesmente da natureza inerente do capital. É, sim, necessário definir as formas modificadas de valor, a existência nacional-estatal do capital, na qual a lei geral do capital atinge sua inflexão no mercado mundial. A forma modificada do valor é expressa na atuação dos capitais individuais como um conjunto social total e, também, como fragmento unitário que compóe o todo, buscando a mesma taxa de lucro. Nas duas abordagens, destaca-se a visão dos efeitos modificados da lei do valor em função dos capitais nacionais, que são apresentados como individualizados no mercado mundial, os quais se relacionam com outros capitais nacionais. Pode-se afirmar que ambos, com suas visões integracionistas dos capitais, entendem a concorrência (e a anarquia dos mercados) como apenas a aparência, a superfície do mercado mundial e não como um traço constitutivo do modo de produção capitalista. Enquanto que a abordagem de Braunmühl é totalizante. As esferas nacional e internacional são vistas como um todo, desempenhando a concorrência entre as unidades políticas apartadas e em coletividade (Estado-nação) o papel essencial na dinâmica da lei do valor. Por amalgamar suas críticas a seus contemporâneos, a compreensão do pensamento de Braunmühl passa pelo enfoque em Neusüss, principalmente, e Busch.

\section{Neusüss, imperialismo e movimento de capitais}

Christel Neusüss tem relevância não apenas no debate do mercado mundial, mas no da derivação do Estado como um todo, pois é coautora do artigo fundacional do tema, ao lado de Müller, em 1970. Após influente carreira nestas discussões, redirecionou seus últimos escritos às questóes dos feminismos. No livro Imperialismus und Weltmarktbewegung des Kapitals (1972), traça suas principais diretivas teóricas. Procura desenvolver as categorias do movimento do capital no 
mercado mundial, cuja base é constituída pela trajetória histórica concreta da relação entre os Estados capitalistas desde o pós-Segunda Guerra.

$\mathrm{Na}$ tentativa de reconstrução da lei do valor marxiana, Neusüss estende-a à esfera internacional. Para ela é preciso partir de Marx e ultrapassá-lo. O alemão trabalha com as leis de movimento do capital em geral, enquanto uma análise apurada do imperialismo requer o foco nos efeitos concretos da lei do valor no mercado mundial. O processo tendencial da equivalência da taxa de lucros por meio da concorrência na esfera da circulação conduz no plano estatal à formação de um complexo capital unificado, que irá atuar na arena internacional.

A autora sustenta a separação entre as esferas de circulação interna e externa, delineando atuaçôes distintas do Estado em cada âmbito em relação aos capitais. A intervenção de questôes não econômicas, que são externas ao movimento dos capitais, é vista como o obstáculo que impede a plena realização das tendências econômicas (NEUSÜSS, 1972). A modificação da lei do valor pela separação dos Estados em unidades nacionais limitadas por fronteiras é complementada pelo movimento da taxa de câmbio (dinâmica válida apenas para o cenário internacional). $\mathrm{O}$ circuito de troca mercadoria-dinheiro-mercadoria transmuta-se em mercadoria-dinheiro-divisamercadoria no mercado mundial. Ou seja, o câmbio nacional atua diretamente na cadeia da troca mercantil. O que torna o contexto ainda mais delicado.

Neusüss acerta na verificação do surgimento histórico do modo de produção capitalista, de imposição da lei do valor, mas a estende erroneamente quando foca no capital em sua meta de converter-se em capital social total mundial, sem considerar a especificidade das lutas de classes e frações.

\section{Busch, empresas multinacionais e movimento de capitais}

Klaus Busch aproxima-se consideravelmente das perspectivas de Neusüss, complementando-as frequentemente. A convergência mais notória é o entendimento do mercado mundial enquanto um âmbito que reúne a combinação de diferentes esferas nacionais de circulação, com a tendência de formação de um capital social total nacional que compete com seus congêneres internacionalmente. Em outras palavras, repete a dualidade das esferas de circulação e a concepção somatória, entendendo o mercado mundial como o total das partes nacionais que o compóem. A obra mais relevante do alemão para o assunto é Die multinationale Konzerne. Zur Analyse der Weltmarktbewegung des Kapitals (1974). Busch, por sua vez, ressalta a importância dos conglomerados multinacionais, apontando o mercado mundial 
como fatiado em esferas de circulação nacionais e distintas entre si. Entende que na esfera internacional há um movimento em direção da equalização das taxas de câmbio, que se tornam um mecanismo protetivo para os capitais nacionais, a depender de sua estratégia internacionalizante. Isso leva à possibilidade, inclusive, de países menos desenvolvidos conseguirem constituir setores exportares de excelência na competição internacional ${ }^{13}$.

Sua análise situa-se no pós-1945, notadamente, no papel dos Estados Unidos enquanto potência dominante no mercado internacional capitalista. Chama a atenção em sua argumentação para a preponderância estadunidense, sem paralelo na trajetória capitalista, refletida no dólar como moeda central do sistema monetário-financeiro, na produção industrial, nas exportaçôes de mercadorias e, fundamentalmente, na exportação de capitais, que se estendeu para além do hemisfério americano, alcançando as potências da Europa Ocidental (BUSCH, 1974). Nesse sentido, enfatiza os investimentos direitos dos norte-americanos em território europeu, como estratégia de internacionalização do mais-valor da produção. Logo, os pilares de discussão de Busch são as causas, as consequências e as perspectivas da internacionalização do mais-valor da produção sob a dominância do capital estadunidense.

Busch e Neusüss tangenciam-se constantemente, a despeito de pontuais diferenciaçôes. O ponto principal é a compreensão do mercado mundial como um universo composto de blocos individualizados de capitais nacionais que encontram com seus congêneres de outras naçóes, produzindo duas esferas de análise, a interna e a internacional, em que a lógica de uma tende a se replicar na outra. Em outras palavras, apesar de estarem inseridos no debate do mercado mundial, Neusüss e Busch ainda estão atrelados ao nacionalismo metodológico, sendo o Estado-nação seu ponto de partida e de análise. Ademais, a concepção que apresentam da forma política não é ainda a mais sofisticada, pois compreendem o Estado como um ente fora e ao lado das relaçôes capitalistas, o qual pode e deve intervir para moldar seus efeitos, em um viés ainda deveras economicista.

\footnotetext{
${ }^{13}$ Sobre essa questão, Busch é alvo de contestaçóes, como as apresentadas por Nachtwey e Ten Brink (2008). Com fulcro nessa premissa, que desconsidera aspectos políticos e econômicos relevantes, ele calca sua crítica às teorias das trocas desiguais, afirmando não haver mecanismos assimétricos de trocas, mas quantidades distintas empregadas de trabalho e de capital/tecnologia.
} 


\section{Braunmühl, mercado mundial e imperialismo}

Claudia von Braunmühl diverge dos dois referidos autores, afirmando-se em uma reflexão própria e original. Alicerçada na economia política marxiana, a autora retoma os esparsos parágrafos legados por Marx, ao longo de sua vasta obra, sobre o mercado mundial para atingir o cerne da compreensão do Estado no capitalismo. Ela diferencia-se de seus pares ao mesclar a discussão com elementos da teoria materialista do Estado, construindo sua articulação teórica e inaugurando a visão materialista do imperialismo.

Não obstante a fecundidade de suas premissas, a alemã, no auge do debate do mercado mundial, limitou-se, todavia, a três ensaios específicos sobre o tema das relações internacionais (BRAUNMÜHL, 1973, 1974 e 1976), bem como a seus desdobramentos ${ }^{14}$, redirecionando suas pesquisas a partir da década de 1980 para outras searas das ciências sociais (como questôes de gênero e de governança global). A despeito de seu destino ter seguido a tendência à entropia, atinente a todo o debate da derivação do Estado e do mercado mundial, arquivados com a guinada neoliberal do sistema internacional, as ideias da autora persistiram pelo tempo e resistiram às dificuldades, podendo, agora, ser resgatadas ${ }^{15}$.

A contribuição de Braunmühl é fértil para a teoria marxista do Estado e para as Relações Internacionais, principalmente. Até então aqueles que se dedicavam à teoria marxista do Estado relegavam a esfera interacional de acumulação, tomando o Estado-nação, a economia nacional ou o capital nacional como ponto de partida. A cientista política alemã é a destacada ao insistir que o nível analítico apropriado para a compreensão do Estado é o mercado mundial ${ }^{16}$. É na dimensão internacional da

${ }^{14} \mathrm{O}$ ensaio de 1974 constitui pedra angular na teorização de Braunmühl, tanto que foi traduzido pela o inglês, com algumas revisóes (alguns trechos do artigo de 1976 são inseridos), sendo publicado em 1978, com o título On the analysis of the Bourgeoise Nation State within the World Market context. An attempt to develop a methodological and theoretical approach. Nesse momento, há o reconhecimento da doutrinadora como um dos expoentes principais da escola da derivaçáo, irradiando seus cânones pelo mundo. Devido a seu impacto e a sua centralidade no pensamento da autora, esse texto é retomado mediante sua tradução para o espanhol, a qual foi publicada em 1983, como Mercado mundial y Estado nación, viabilizando a porosidade das ideias pela América Latina.

${ }^{15}$ Nachtwey e Ten Brink (2008) lamentam tanto o fato de o debate ter se perdido no tempo, que escreveram um artigo reverenciando e resgatando o tema, o qual é a referência citada, quanto os três ensaios de Braunmühl não terem se tornado uma obra singular, mas terem ficado esparsos em artigos. ${ }^{16}$ Obviamente aqui não podemos desconsiderar o pioneirismo e o brilhantismo das análises de Wallerstein, de Frank, de Dos Santos e de Amin sobre a reconstrução da história do capitalismo como um sistema mundial e o modo de produção capitalista como um processo de acumulação mundial. $\mathrm{O}$ 
acumulação, no mercado mundial que se deve derivar ou determinar a forma do Estado burguês. Acumulação, reprodução e expansão do capital não podem ficar aprisionadas às fronteiras nacionais (FAY e STUCKEY, 1980).

Também não há razões para se estabelecer a identidade entre Estado e capital, haja vista que o capital (internacional) é organizado e particularizado pelo Estado, dentro de fronteiras nacionais, ganhando a forma de capital nacional, em meio a peculiaridades históricas das lutas sociais. Dessa maneira, a compreensáo plena do Estado e do capitalismo passa pelas relações internacionais como um todo. A forma mercado mundial é o modo de existência das relaçôes nacionais; estas subsistem em e por meio das relações do mercado mundial, logo este não é um elemento externo às naçôes, mas sua base e sua atmosfera vital (BONEFELD, 2013).

O centro nevrálgico é: o Estado não existe no singular, mas apenas na forma de um sistema de Estados nacionais. Ela argumenta que a dinâmica ilustrada entre Estado e capital não é resultado do desenvolvimento moderno do capitalismo ou do que se veio a chamar de globalização, mas é inerente da própria forma nacional do Estado, a qual deve ser derivada do mercado mundial, âmbito da manifestação plena do modo de produção capitalista, de contexto marcado forçosamente por dois aspectos: pela acumulação global capitalista (essencialmente contraditória) e pelo sistema internacional de Estados (plural e concorrencial).

Ela defende que não basta derivar a forma política e o Estado das relações sociais capitalistas, mas é fulcral ir além e fomentar o estudo da forma de particularização estatal, de suas especificidades. Se a política modifica a lei do valor, o limite da intervenção estatal não pode ser entendido sem que se tenha em mente os limites da forma nacional do Estado. Não há como apreender as especificidades e a essência estatal sem tocar a forma do Estado-nação, inserido no contexto de acumulação global de capital e no sistema capitalista de Estados, ou seja, o mercado mundial (BRAUNMÜHL, 1976).

O destaque dado a Braunmühl deve-se à abordagem totalizante e inovadora que a inscreve no preenchimento da lacuna da teoria marxista do Estado quanto à dimensão internacional ${ }^{17}$. As esferas nacional e internacional são vistas como um

que se enfatiza na visão de Braunmühl é o pensamento sobre a teoria marxista do Estado sob os cânones do mercado mundial.

${ }^{17}$ Nessa linha, coube a Barker (1991), no cenário britânico, tecer acompanhamentos e complementos ao raciocínio. Ele também insiste que a análise da forma estatal deve partir do capital em geral ao nível do mercado mundial. Diferentemente de Braunmühl, Barker (1991) não retoma a formação histórica 
todo, desempenhando a concorrência entre as unidades políticas apartadas e em coletividade (Estado-nação) o papel essencial na dinâmica da lei do valor. Em seu método, ao invés de partir do capital nacional e do Estado-nação individualizado (nacionalismo metodológico), propóe a análise do Estado, tomando como base a forma mais desenvolvida de capitalismo, o mercado mundial enquanto uma totalidade, um universo plural, composto por Estados nacionais individualizados, mas que não é o resultado automático da soma de todos eles. Não há que se derivar a configuração do mercado mundial dos capitais nacionais, mas de seu todo. $\mathrm{O}$ mercado mundial não é constituído por várias economias nacionais reunidas, mas é organizado na forma política da multiplicidade de economias nacionais como seus componentes integrais. É nesse âmbito que os capitais realmente se movem, logo, é partindo dele que se deve analisar a lei do valor, o que significa inserir a derivação da forma do Estado burguês dentro desta dimensão. A plena compreensão da forma estatal não pode ficar restrita às fronteiras nacionais da sociedade produtora de mercadorias. Uma vez que a esfera mais desenvolvida de movimento de capital e da lei do valor é o mercado mundial, é dele que se deve partir (BRAUNMÜHL, 1973).

O mercado mundial é o substrato do qual se extraem todas as categorias da crítica marxiana da economia política. É ao mesmo tempo a precondição e o resultado da produção capitalista. Asseverando o caráter intrinsecamente internacional do modo de produção capitalista, a base do Estado nacional só pode ser o mercado mundial; e este, por sua vez, só existe nos e a partir de espaços nacionalmente organizados. $\mathrm{O}$ impulso à fortificação do mercado mundial é dado pela competição entre capitais, que utilizam todos os meios possíveis disponíveis (como a constante reorganização do Estado para garantir condiçôes de valorização) na busca por lucros. Essa dinâmica leva à cristalização de múltiplos centros de acumulação moldados em Estados-nação.

Ela deve partir das categorias gerais, que Marx desenvolveu n’O Capital para a anatomia da sociedade burguesa, mas não deve ficar a elas restrita, e, sim, seguir, conforme o método do abstrato ao concreto, por uma derivação categorial determinada do movimento aparente na superfície da sociedade, a mudança de forma da concorrência no âmbito mundial, do desenvolvimento e da diferenciação de classes, da forma da luta de classes e da consciência social dos atores, dos quais devem ser investigados

dos Estados, mas enfatiza que cada espaço nacional representa a fusão de uma fração particular do capital mundial com segmentos de classes nacionais em oposição e em competição a outras nações. 
e determinados a estrutura política do sistema e do real curso do processo político. (BRAUNMÜHL, 1973, p. 7-8, tradução nossa).

Reitera-se que pelo viés marxiano, o mercado mundial apresenta-se como um esquema distinto das relações de produção entre os países (as relações internacionais propriamente ditas, em sentido estrito), uma dimensão mais ampla, em verdade. Não fortuitamente, desde seus primeiros esboços, o mercado mundial aparece como ponto concluinte da anatomia da sociedade capitalista, visto que é lá onde todas as contradições da sociabilidade burguesa se póem em jogo, manifestando sua mais concreta materialidade. Logo, o mercado mundial configura a forma universal de existência capitalista. Nesse espaço, o trabalho humano é levado aos mais elevados níveis de abstração, em termos de enquadramento na constante revolução das relaçôes de produção, na concorrência constante pela valorização do valor. Assim, o mercado mundial constitui em geral a base e a atmosfera vital do modo de produção capitalista, não sendo uma categoria econômica como outras, mas é, ao mesmo tempo, o pressuposto e o resultado das relaçóes capitalistas. Por conseguinte, o mercado mundial não é externo às relações nacionais de exploração, mas ele subsiste e fomenta a exploração nos territórios nacionais e por meio do controle político estatal (BONEFELD, 2013). Nessa dinâmica, pode-se afirmar que o Estado capitalista não existe no singular, somente em coletividade (BARKER, 1991).

Assim como o capital em geral ilustra a contradição entre anarquia (na competição entre capitais) e despotismo (controle dentro de cada capital individual), a cena política carrega também a unidade contraditória entre despotismo (soberania estatal dentro dos territórios nacionais) e anarquia (competição interestatal). O Estado configura-se, por conseguinte, como um vetor privilegiado da competição intracapitalista no mercado mundial. Por isso, ele será atravessado pela contradição entre a tendência à internacionalização dos capitais e à nacionalização da organização capitalista por meio de um sistema político de intervençôes estatais nas relações de produção (JESSOP, 1982).

Braunmühl, em consonância com a nova leitura de Marx, extrai das categorias da economia política e da própria forma do capital, bem como das relaçôes de produção capitalistas, o entendimento das estruturas políticas que lhe são próprias, como o Estado. E vai além, voltando seu foco para as relaçóes internacionais (em sentido amplo). O mercado mundial é o substrato do qual se extraem todas as categorias da crítica marxiana da economia política. É ao mesmo tempo a precondição e o resultado da produção capitalista. Asseverando o caráter 
intrinsecamente internacional do modo de produção capitalista, a base do Estado nacional só pode ser o mercado mundial; e este, por sua vez, só existe nos e a partir de espaços nacionalmente organizados.

A relevância dessa abordagem não foi de pronto captada pelos principais cânones teóricos, abrindo uma lacuna na teoria marxista sobre o assunto, a qual foi alvo preferencial de críticas ${ }^{18}$. E mesmo entre aqueles que conferiram todo o mérito à pensadora pela abordagem sistemática, as contestaçóes não foram poupadas ${ }^{19}$. Independentemente da repercussão gerada, o que por ora interessa é apontar os ensinamentos que ficaram.

\section{Conclusões}

$\mathrm{O}$ ressurgimento de uma vertente alternativa às teorias marxistas do Estado postas até então confere novo fôlego às investigaçôes da forma política no capitalismo. Notadamente, a discussão destrinchada da clivagem entre política e economia própria do modo de produção vigente. Assim, destacam-se o debate derivacionista do Estado e sua vertente do mercado mundial.

O capitalismo constitui-se em sua forma mais desenvolvida no sistema internacional. O mercado mundial é o âmbito de manifestação mais alargada do capitalismo. É a arena que capta os fenômenos capitalistas por completo. É a base e a atmosfera de vida do modo de produção capitalista. O Estado capitalista não surge isoladamente, mas em coletivo, enquanto um sistema de Estados, sendo essa multiplicidade um traço estrutural do capitalismo. O espaço geográfico do capital não é o das fronteiras estatais, senão o internacional.

Com efeito, a forma política capitalista toma molde de Estado-nação, em um ambiente de múltiplos atores congêneres (OSORIO, 2018). Logo, a discussão sobre a

\footnotetext{
${ }^{18}$ Nessa linha, coube a Barker (1991), no cenário britânico, tecer acompanhamentos e complementos ao raciocínio. Ele também insiste que a análise da forma estatal deve partir do capital em geral ao nível do mercado mundial. Diferentemente de Braunmühl, Barker (1991) não retoma a formação histórica dos Estados, mas enfatiza que cada espaço nacional representa a fusão de uma fraçáo particular do capital mundial com segmentos de classes nacionais em oposição e em competição a outras naçóes.

19 Fay e Stucker (1980) dirão que a autora levanta a questão correta, mas lhe dá uma resposta equivocada, quando partindo de uma abordagem deveras eurocentrista, náo considera a estrutura básica desigual do sistema mundial, a divisão entre um centro acumulador e explorador e uma periferia não acumuladora e explorada. A ausência do olhar para a periferia faz com que a autora relegue a maioria dos países do mercado mundial, abarcando somente a realidades das poucas potências centrais, o que acaba maculando sua abordagem do capitalismo como sistema mundial.
} 
forma política capitalista toca o Estado enquanto aparato de dominação de classe e como aparato de competiçáo entre segmentos das burguesias. O Estado no capitalismo é moldado na lógica do capital (em uma relação factual contraditória), sendo despótico em relação a seus sujeitos (nacionais), e competitivo, e imerso na anarquia, em meio a seus rivais (congêneres estatais). Essa forma política concreta expressa que o Estado capitalista não está acima e fora das relações capitalistas de produçáo, mas é decorrência direta delas. O capitalismo é anarquicamente ingovernável (não há um centro nevrálgico de comando que guie seus rumos). Nenhum centro ou instituição irá controlá-lo. Suas generalidades são resultados das relaçôes anárquicas de competição entre os capitais em disputa.

Em suma, na cena hodierna, em meio ao acirramento das contradições via desconstituições das miragens modernizantes do capitalismo pós-fordista, é premente revisitar o conceito de Estado, retomando sua grandeza, o que não é uma tarefa simples, mas demanda a assunção de uma postura teórica e prática, que impulsione o leitor para a fuga do conforto das certezas. Diante do cenário de brumas, o debate da derivação do Estado faz-se imperioso por dois motivos. O primeiro é relativo à busca de alternativas ao atual contexto de lutas, restrito aos âmbitos do Estado e do direito. $\mathrm{O}$ segundo toca a necessidade de um horizonte teórico transformador que conduza uma prática voltada às mudanças estruturais.

Cumpre resgatar as lições teóricas aprendidas no passado para que se compreenda o presente e se planeje o futuro, escapando de modismo e de soluções convenientes. $\mathrm{O}$ estudo do conceito-chave do capitalismo em meio às diversas abordagens e às transformaçôes históricas fornece alternativas teóricas para impulsionar o motor da história. A caminhada é rumo à superação da miséria capitalista e ao estabelecimento de novos horizontes de mundo.

- Luiz Felipe Osorio é Pós-Doutor em Direito Político e Econômico pela Universidade Presbiteriana Mackenzie/SP e Doutor em Economia Politica Internacional pela Universidade Federal do Rio de Janeiro (UFRJ). Professor Adjunto de Direito e Relações Internacionais da Universidade Federal Rural do Rio de Janeiro. Email: 1uizfelipe.osorio@gmail.com. 


\section{Referências}

ALMEIDA, Silvio; CALDAS, Camilo. Revolução Russa, Estado e Direito: abertura para compreensão das formas sociais e das formaçōes econômico-sociais. Direito e Práxis. Rio de Janeiro, v. 08, n. 3, p. 2377-2404. 2017.

ANDERSON, Perry. Consideraçóes sobre o marxismo ocidental: nas trilhas do materialismo histórico. São Paulo: Boitempo, 2004.

ALTVATER, Elmar; HOFFMANN, Jürgen. The West Germany State derivation debate: the relation between economy and politics as a problem of Marxist State theory. Social Text. v., n. 24, p. 134$155,1990$.

BARKER, Colin. A note on the theory of capitalist States. In: CLARKE, Simon (Org.). The State debate. Palgrave Macmillan, 1991, p. 182-191.

BONEFELD, Werner. Más allá de las relaciones internacionales: acerca del mercado mundial y el estado-nación. In: KAN, Julián; PASCUAL, Rodrigo (Orgs.). INTEGRADOS (?) Debates sobre las relaciones internacionales y la integración regional latino-americana y europea. Buenos Aires: Imago Mundi, 2013, p. 43-70.

BONEFELD, Werner; HOLLOWAY, John. Introduction: Post-Fordism and social form. In: - Post-Fordism \& social form. A Marxist debate on the Post-Fordist State. London: Macmillan Academic and Professional LTD, 1991, p. 1-7.

BONNET, Alberto. Estado y capital: debates sobre la derivación y la reformulación del Estado. In: THWAITES-REY, Mabel (Org). Estado y marxismo: un siglo y medio de debates. Buenos Aires: Prometeo Libros, 2007, p. 269-296.

BONNET, Alberto; PIVA, Adrián. Prólogo. In: . (Orgs.). Estado y capital. El debate alemán sobre la derivación del Estado. Buenos Aires: Herramienta Ediciones, 2017, p. 9-26.

BRAUNMÜHL, Claudia von. Weltmarktbewegung des Kapitals, Imperialismus und Staat. In: BRAUNMÜHL, Claudia von; FUNKEN, Claus; COGOY, Mario; HIRSCH, Joachim. Probleme einer materialistische Staatstheorie. Frankfurt am Main: Suhrkamp, 1973, p. 11-91.

. Kapitalakkumulation im Weltmarktzusammenhang. Zum methodischen Ansatz einer Analyse des bürgelichen Nationalstaats. In: ERBERLE, Friedrich (Org.). Gesellschaft: Beiträge zur Marxschen Theorie. Frankfurt am Main: Suhrkamp, 1974, p. 30-51.

Die nationalstaatliche Organisiertheit der bürgerlichen Gesellschaft. Ansatz zu einer historischen und systematischen Untersuchung. In: ERBELE, Friedrich (Org.). Gesellschaft. Beiträge zur Marxschen Theorie, Frankfurt am Main: Suhrkamp, 1976, p. 273-334.

. On the analysis of the the bourgeois nation State within the world market context. In:

HOLLOWAY, John; PICCIOTTO, Sol (Orgs.). State and Capital: a Marxist debate. Londres: Edward Arnold, 1978, p. 160-177.

. Mercado mundial y Estado nación. Cuadernos Políticos, nº 35. México, D.F., Ediciones Era, p. 4-14, enero-marzo, 1983.

BUSCH, Klaus. Die multinationalen Konzerne- zur Analyse der Weltmarktbewegung des Kapitals. Frankfurt am Main: Suhrkamp Verlag, 1974.

CALDAS, Camilo Onoda Luiz. Teoria da derivação do Estado e do direito. São Paulo: Outras Expressôes; Dobra Univeritária, 2015.

CARNOY, Martin. Estado e teoria política. Campinas-SP: Editora Papirus, 1994. 
CLARKE, Simon. The State Debate. In: CLARKE, Simon (Org.). The State Debate. Londres: Palgrave Macmillan, 1991, p. 1-61.

ELBE, Ingo. Marx im Westen: Die neue Marx-Lektüre in der Bundesrepublik seit 1965. Berlim: Akademie, 2010.

FAY, Margaret; STUCKEY, Barbara. A friendly critique of Claudia von Braunmühl's On the Analysis of the Bourgeoise Nation State within the World Context: an attempt to develop a methodological and theorical approach. Kapitalistate. v. 1 n. 8. Focus: Democratic Struggles and the State. Berkeley, p. 138-147, 1980.

GERSTENBERG, Heide. The Historical Constitution of the political forms of capitalism. Antipode. A Radical Journal of Geography. v. 43, n. 1, p. 60-86, 2010.

HIRSCH, Joachim. Teoria Materialista do Estado: processos de transformação do sistema capitalista de Estados. Rio de Janeiro: Editora Revan, 2010.

HIRSCH, Joachim; KANNANKULAM, John; WISSEL, Jens citar. A teoria do Estado do marxismo ocidental. Gramsci, Althusser e Poulantzas e a chamada derivação do Estado. Revista Direito e Praxis. Tradução de André Vaz Porto Silva. Revisão técnica de Luiz Felipe Brandão Osório. Vol. 08, $\mathrm{n}^{\mathrm{o}} 1$, Rio de Janeiro, 2017, p. 722-760.

HIRSCH, Joachim. Retrospectiva sobre el debate. In: BONNET, Alberto; PIVA, Adrián (Orgs.). Estado y capital. El debate alemán sobre la derivación del Estado. Buenos Aires: Herramienta Ediciones, 2017, p. 27-38.

HOLLOWAY, John. El debate sobre la derivación del Estado. Una reflexión reminiscente. In: . (Orgs). Estado y capital. El debate alemán sobre la derivación del Estado. Buenos Aires: Herramienta Ediciones, 2017, p. 39-46.

JESSOP, Bob. The capitalist State: Marxist theories and methods. Oxford: Martin Robertson \& Co., 1982.

JESSOP, Bob. Regulation theory, post Fordism and the State. More than a reply to Werner Bonefeld. In: BONEFELD, Werner; HOLOWAY, John. Post-Fordism \& social form. A Marxist debate on the Post-Fordist State. London: Macmillan Academic and Professional LTD, 1991, p. 69-91.

MARX, Karl. O Capital. Crítica da Economia Política. Livro I: o processo de produção do capital. São Paulo: Boitempo, 2013.

MASCARO, Alysson Leandro. Estado e Forma Política. São Paulo: Boitempo Editorial, 2013.

MASCARO, Alysson Leandro. Crise e Golpe. São Paulo: Boitempo Editorial, 2018.

MÍGUEZ, Pablo. El debate conteporáneo sobre el Estado en la teoría marxista: su relación con el desarollo y la crisis del capitalismo. Estudios Sociológicos de el Colegio de México, v. 28, n. 84, p. 643-689, 2010.

MÜLLER, Wolfgang; NEUSÜSS, Christel. The Welfare-State Illusion and the contradiction between wage labour and capital. In: HOLLOWAY, John; PICCIOTTO, Sol (Orgs.). State and Capital: a Marxist debate. Londres: Edward Arnold, 1978, p. 32-39.

NACHTWEY, Oliver; TEN BRINK, Tobias. Lost in Translation. The German World Market Debate in the 1970s. Historical Materialism. v. 16, n. 1, p. 37-70, 2008.

NEUSÜSS, Christel. Imperialismus und Weltmarktbewegung des Kapitals. Erlangen: Politladen, 1972.

OSORIO, Luiz Felipe Brandão. Imperialismo, Estado e Relaçôes Internacionais. São Paulo: Editora Ideias e Letras, 2018. 
PACHUKANIS, Evguiéni. Teoria Geral do Direito e Marxismo. São Paulo: Editora Boitempo, 2017. PEREIRA, Luiz Ismael; ERKERT, Jonathan Erik von. Uma radiografia marxista do Estado e do direito. Margem Esquerda. No 26. São Paulo: Boitempo, $1^{\circ}$ semestre de 2016, p. 147-150.

Texto recebido em 09 de julho de 2018. Aprovado em 06 de fevereiro de 2019. 